\title{
The Kingdom of Saudi Arabia: Achieving the Aspirations of the National Transformation Program 2020 and Saudi Vision 2030 Through Education
}

\author{
Brendan Mitchell ${ }^{1} \&$ Abdulrahman Alfuraih ${ }^{2}$ \\ ${ }^{1}$ Education Developer, Kingdom of Saudi Arabia \\ ${ }^{2}$ Head of English Language Department, Ministry of Education, Kingdom of Saudi Arabia \\ Correspondence: Brendan Mitchell, Education Developer, Kingdom of Saudi Arabia.
}

Received: December 1, 2018

Accepted: December 18, 2018 Online Published: December 24, 2018

doi:10.20849/jed.v2i3.526

URL: https://doi.org/10.20849/jed.v2i3.526

\begin{abstract}
The research described and reported on in this article focuses on an analysis of the Saudi Arabian National Transformation Program 2020 and Saudi Vision 2030. The investigation involved a document analysis of these documents in order to identify the associated curriculum orientations within these documents to determine what the Kingdom of Saudi Arabia is seeking to achieve and how it envisages achieving these aspirations through education development. The analysis revealed that the goals and aspirations of the Kingdom have increasingly become more clearly defined with attention to alignment between national education goals and economic development whilst ensuring that practices are consistent with Islamic beliefs. In brief, as evidenced in the documents, the analysis reveals that the imperative of the National Transformation Program 2020 and Saudi Vision 2030 is to establish a 'Saudized' knowledge-based economy; and education is seen to be a means by which this imperative is to be fostered.
\end{abstract}

Keywords: National Transformation Program 2020, Saudi Vision 2030, document analysis, Kingdom of Saudi Arabia

\section{Introduction}

This article presents the results of a document analysis commencing with an overview of the Kingdom of Saudi Arabia's Ninth Development Plan (2010 - 2014), which provides the background to government and ministerial strategy, goals, objectives, and focus in the Kingdom. This document illustrates how the Kingdom's development plans have been structured and have become more complex and ambitious. The article infers that the Kingdom's Tenth Development Plan $(2015$ - 2019) is perhaps less relevant and important than preceding plans because of the 2016 release of the Kingdom's defining documents; the National Transformation Program 2020 and the Saudi Vision 2030. These documents were selected for analysis to exemplify how economic development and 'Saudization' is explicitly linked education. Commentary on the release, content, and intention of both the National Transformation Program 2020 and the Saudi Vision 2030 was overwhelmingly supportive, positive, and complementary nationally, regionally, and globally because of the opportunities outlined in these documents for the current and future generations. They provide a 'roadmap' for the Kingdom to economically and financially diversify.

There is nothing new about the concept and intention of economic programs and visions, particularly regionally, with fellow Gulf Cooperation Council Countries Oman, Kuwait, the United Arab Emirates, and Bahrain all having vision documents or plans to contribute to transforming their nations and opportunities for their citizens. However, the Kingdom of Saudi Arabia is the largest regional economy and has substantial resources to draw upon to realize the goals and aspirations of its Vision through the continued up-skilling of its citizens and the mobilization of a Saudized dominated private sector.

\section{Orientations to Curriculum}

Eisner's (1985) five orientations to curriculum provided the framework for the document analysis. The first curriculum orientation academic rationalism argues that, "the major function of the school is to foster the intellectual growth of the student in those subject matters most worthy of study" (Eisner, 1985, p.66). The 
second orientation, the cognitive processes orientation emphasizes the function of curriculum is to guide children's learning and improve the intellectual capabilities they have (Eisner, 1985). Eisner's third orientation to curriculum is personal relevance where students have influence on curriculum in that courses are designed so that students have an input in determining the personal significance a course will have for them. For example, the personal significance could be comprised of elective components both in subject matter and assessments where students' influence, amongst other things the teaching and learning process.

Eisner's (1985) fourth orientation to curriculum draws attention to two social imperatives - social adaptation and social reconstruction, both of which are strongly evident in curriculum initiatives in today's global education reform movement. Social adaptation has two distinct segments in society; the first, "regards the manpower needs of society as most salient" (Eisner, 1985, p. 74). This segment infers that when skills are needed in a certain area it is the role of education providers to produce suitability qualified personnel to meet a skill shortage or need. The second segment of social adaption is "the need for conformity to exiting values and for children to take their place in social order" (Eisner, 1985, p. 74). Social reconstruction "is basically aimed at developing levels of critical consciousness among children and youth so that they become aware of the kinds of ills that society has and become motivated to learn how to alleviate them" (Eisner, 1985, p. 76). Eisner's final orientation is curriculum as technology where the focus is on curriculum planning, purpose, and goals with an emphasis on evaluation of the efficiency and effectiveness of the curriculum.

\section{Methodology}

Eisner's (1985) orientations to curriculum provided the foundation for the methodology, a document analysis, an analytical qualitative research method for reviewing and evaluating documents (Bowen, 2009). The Kingdom of Saudi Arabia's Ninth Development Plan (2010 - 2014), National Transformation Program 2020, and Saudi Vision 2030 were analyzed, examined, and interpreted to extract meaning. In brief, these documents were identified and coded through a content analysis (Labuschagne, 2003) based on sharing similar principles and goals (Manley-Delacruz, 1990).

The document analysis was directed by Braun and Clarke's (2006) six phase thematic analysis process: familiarization with the (categorized) data set; generating initial data; searching for themes; checking identified themes; refining themes; and reporting on these findings. This six-step process is evident in the results and discussion to follow. Braun and Clarke's (2006) process provided a flexible approach to conduct the data analysis, which sort out common themes to emerge in the curricula and supporting documents using Eisner's (1985) orientations to curriculum to analyze the documents.

Through the use of both Braun and Clarke's (2006) thematic analysis process and Eisner's (1985) curriculum orientations the goals of the National Transformation Program 2020 and Saudi Vision 2030 of what the Kingdom of Saudi Arabia is aiming to achieve through education development efforts become apparent. The methodology employed enables the article to explore a key question: What is the Kingdom of Saudi Arabia seeking to achieve through the identified education initiatives in the National Transformation Program 2020 and Saudi Vision 2030? The aims and goals of the documents that have emerged from the analysis are discussed in the results section and synthesized in the discussion section of the paper.

\section{Results}

This results section is divided into two main sections. The first presents the data from the analyses of the broad aims and goals of the three documents analyzed. The second section of the article provides a discussion and presents the broader outcomes, findings, and themes that have arisen through the document analysis.

\section{Ninth Development Plan (2010 - 2014)}

Prior to the release of the the National Transformation Program 2020 and Saudi Vision 2030 the Kingdom of Saudi Arabia used five year development plans to report on achievements, statistics, and present the goals and objectives of the Kingdom for the proceeding five years. There is some information available on a Tenth Development Plan (2015-2019) but less than its predecessors as the focus of the Kingdom is on commitment to realizing the aspirations of the National Transformation Program 2020 and Saudi Vision 2030 through national support, citizenship, and engagement of its citizens.

This section of the article presents an overview of the content of the Ninth Development Plan (2010 - 2014) to provide the readership with an informed understanding of the structure and content of Saudi Arabian development plans. The Ninth Development Plan $(2010$ - 2014) is a detailed, high level policy document concerned with economic development, improved efficiency, and increased participation in the private sector by Saudis to support Saudization, technological advancement, and improving the outputs of the education sector. 
The preface recognizes the size and importance of the Saudi Arabian economy in the world along with commending the validity and efficacy of the development process pursued, cumulating in the Kingdom of Saudi being a member of the 20 largest economies (G20) and Global Financial Security Board. The Ninth Development Plan $(2010$ - 2014) was formulated in the midst of the Global Financial Crisis. However, the plan demonstrated the commitment and determination of the leaders to accelerate the development achieved over the last decade, particularly during the Eighth Development Plan (2005 - 2009). The Ninth Development Plan (2010 - 2014) was built on five key areas, which form an integrated framework for balanced, comprehensive, and sustainable long term development. The five themes are: (1) continual improvement in the standard of living and quality of life for citizens; (2) development of national human resources and employment opportunities for citizens; (3) balanced development throughout the Kingdom; (4); structural development of the Saudi economy and (5) improving the competitiveness of the national economy in conjunction with Saudi products in both the domestic and external markets (Ninth Development Plan, 2010).

Academic rationalism, social adaptation, and curriculum as technology dominate the curriculum orientations that have been identified in the Ninth Development Plan $(2010$ - 2014) to contribute to meeting the Kingdom of Saudi Arabia's goals. The Ninth Development Plan (2010 - 2014) aimed to develop science, technology, engineering, and mathematics to enhance a knowledge-based economy; improve academic standards; continue to improve of the content and structure of the curriculum; provide professional development for teachers; construct and develop school buildings to include technology facilities; develop students' who are capable of competing internationally in science and technology; and eradicate illiteracy, which are aligned with academic rationalism. The focus is on improving standards and knowledge of both teachers and students; developing science, technology, engineering, and mathematics subjects to support a knowledge-based economy; improving the outcomes of graduates; and producing students who are able to compete internationally in science and technology fields. To support these objectives, continuous improvement in the content and structure of curricula is seen as crucial along with the recognition that school buildings need to be developed and refurbished to improve the teaching and learning environment, and keep up with advances in technology.

The curriculum orientation development of cognitive processes, which develops the students' creativity and problem solving skills, are aligned with the aims in the Ninth Development Plan $(2010$ - 2014) of developing students' creativity, research ability, and the self-learning abilities of students. The curriculum orientation social adaptation is well represented as it is linked to the economic needs of the Ninth Development Plan (2010 - 2014) placing importance on developing and improving human resources to meet the Kingdom's economic needs.

\section{National Transformation Program 2020}

The National Transformation Program 2020 is a program by the Saudi Vision 2030 and the foreword of the document describes some of the key areas the program seeks to concentrate on and how the Kingdom will address them through the identification of general directions, policies, goals, and objectives of the Kingdom. The National Transformation Program 2020 was launched in 2016 across 24 government bodies and its strategic objectives are linked to interim targets to be achieved by 2020. The program seeks to identify challenges government entities may encounter or may hinder them in achieving the Saudi Vision 2030, and established 2020 targets; development of initiatives designed to achieve documented goal outcomes; development of implementation plans; promote transparency; and strive for continual improvement.

"The Program uses innovative methods to identify challenges, seize opportunities, adopt effective planning tools, activate the role of the private sector, bring about implementation, and evaluate performances" (Kingdom of Saudi Arabia, 2016a, p. 7). The program seeks to ensure solid foundations are established for continued action, implementation, and evaluation of projects.

Unlike the national development plans that contained numerous chapters the National Transformation Program 2020 is comprised of two chapters, each of which has clearly defined sections. Chapter 1 describes the plan and includes the following sections: Identity and General Principles of the National Transformation Program; Objectives of the National Transformation Program; Operating Model of the National Transformation Program; National Transformation Program's Participating Entities; Governance Model of the National Transformation Program; and Costs and Revenues of the National Transformation Program. The second chapter presents the goals and targets of the 24 government bodies: Ministry of Justice; Ministry of Finance; Ministry of Economy and Planning; Ministry of Health; Ministry of Communications and Information Technology; Ministry of Commerce and Investment; Ministry of Municipal and Rural Affairs; Ministry of Civil Service; Ministry of Culture and Information; Ministry of Environment, Water, and Agriculture; Ministry of Energy, Industry, and Mineral Resources; Ministry of Labor and Social Development; Ministry of Housing; 
Ministry of Education; Ministry of Transportation; Ministry of Haj and Umrah; Saudi Commission for Tourism and National Heritage; Sports Authority; Royal Commission for Jubail and Yanbu; King Abdulaziz City for Science and Technology; King Abdullah City for Atomic and Renewable Energy; Institute of Public Administration; Saudi Arabian General Investment Authority; and Saudi Food and Drug Authority.

Relevant to all 24 identified government bodies responsible for implementing this five phase program are the key objectives of the National Transformation Plan 2020. These are: identifying the strategic objectives and targets for each of the 24 government bodies; translating the identified objectives and targets into initiatives; and promoting joint action toward the achievement of common national goals through job creation, public-private sector partnerships, maximizing local content, and digital transformation. These key objectives can be seen to be 'target oriented' and 'geared' towards providing opportunities for Saudi citizens and a prosperous future for the Kingdom of Saudi Arabia as it strives to move away from an oil dominated economy and toward a knowledge driven society and economy.

\section{Document Analysis: National Transformation Plan 2020}

Appendix A provides an analysis of the of the key educational related initiatives government bodies are tasked with delivering using Eisner's (1985) orientations to curriculum as pre-defined codes. Appendix A identifies the trends and orientations that have influenced the identified educational goals contained in the strategic objectives of the 24 government bodies in the construction of the National Transformation Program 2020. Not all 24 government bodies are represented in Appendix A because while it could be argued that the achievement of the strategic objectives of all 24 government bodies' are reliant on education this article does not attempt to rationalize this position. Hence, Appendix A includes the strategic objectives directly related to education.

The orientation that dominates the identified curriculum orientations within the National Transformation Program 2020's education related objectives is social adaptation. The National Transformation Program 2020 has a key emphasis on the collective responsibility of education to produce graduates who are work ready to contribute to the Saudization of the workforce, with a particular emphasis on increasing Saudi participation in the private sector. This is being supported by legislation to Saudize jobs and initial measures were put in place prior to the release of the National Transformation Program 2020. For example in 2015, "chief administrator of human resources at government and private sector companies, head of personnel department, director of labor affairs, director of personnel relations, employment clerk, time-keeper, receptionist (general), receptionist (hotel), receptionist (hospitals), cashier, and typist" (Habtor, 2015, para. 3) were additional jobs the Ministry of Labor deemed to be carried out only by Saudis. Further categories that have recently been added to the restricted professions list include: shopping mall jobs, tourism, retail, car rental industry, insurance and banking, watches, eyewear, medical equipment and devices, electrical and electronic appliances, auto parts, building materials, carpets, cars and motorcycles, home and office furniture, children's clothing and men's accessories, home kitchenware, and confectioneries.

These changes in Labor law in conjunction with the aspirations of the Kingdom increasingly provide evidence that the goals of the Kingdom include providing the younger generation with the necessary skills during their education that will support them to become economically productive members of Saudi society as education becomes influenced by the economic agenda (Connell, 2013). "There are 13 million Saudi citizens under the age of 30 representing approximately two-thirds of the population making the Kingdom much younger than most countries" (Boston Consulting Group, 2014 p. 3). The Kingdom's young population will intensify the pressure on the Kingdom of Saudi Arabia to address the concerns of its youth where the Kingdom has very high birth rates (Commins, 2008). The government in the Kingdom can be seen to be addressing the concerns of its youth through education and training, legislation, the National Transformation Program 2020 and the Saudi Vision 2030. In essence the Kingdom has created collective goals and aspirations for its citizens with actions to support these.

\section{Key Education Initiatives within the National Transformation Program 2020}

A complementing key point of difference between preceding national development plans and the National Transformation Program 2020 is in the title; program v plan. That is a plan details a course of action and in the case of Saudi Arabian national development plans they also included past and historical achievements. A program, on the other hand, consists of multiple projects designed to produce outcomes. Hence, included in the National Transformation Program 2020 are key performance indicators, 2020 targets, aligned with regional and global benchmarks. These key performance indicators and the achievement and outcomes of the initiatives are subject to transparency, analysis, and publication of the achievements and outcomes. Additionally, there is an audit function in the Program to report on the progress and achievement of targets. The audit function seeks 
continuous improvement and progress toward initiatives' targets and provides a tool to identify if any early corrective action is required to prevent obstacles from interfering with the achievement of the desired targets.

The National Transformation Program 2020 identifies 36 Ministry of Education initiatives to be implemented under the program, which aim to contribute significantly to the macro objectives of the program and the Vision 2030. These 36 initiatives are: (1) comprehensive framework for continuing professional development for teachers and educational leaders; (2) shift to digital education to support student and teacher progress; (3) increase community clubs' entertainment and educational programs; (4) improve the safety and security in school buildings; (5) reduce the administrative burdens of teachers and education leaders to ensure that they focus on the educational process and to improve the quality of support services; (6) encourage private sector to invest in public education; (7) establish a Transformation Office at the Ministry level to support the

National Transformation program; (8) apply the Ministry of Education's new operating model; (9) develop a national strategy to upgrade the teaching profession by raising the professional level of teachers, improving the profession's ecosystem and raising the quality of services provided to teachers; (10) improve the quality of primary education; (11) development of nurseries and kindergarten programs and the expansion of their services to cover all regions; (12) improve international study scholarship program and improve its efficiency; (13) develop core life and employability skills and integrate it with curricula and extra-curricular activities; (14) establish King Salman University for Technical \& Vocational Education; (15) develop student-centric education model; (16) enhance participation in international scientific competitions; (17) establish technical labs in schools to foster students' vocational skills; (18) attract private investments to finance schools' construction; (19) enhance planning and budgeting efficiency in order to achieve the rationalization of capital and operating expenses; (20) establish a Center for English Language Education Development; (21) establish a Center for Arabic Language Education Development; (22) establish a Center for Development of Healthcare Information System; (23) establish a Center for Science, Technology, Engineering and Mathematics Education Development; (24) project to develop special education/establish a national center dedicated to special education in collaboration with the private sector; (25) establish the e-service framework for universities; (26) establish a practical framework to align university graduates with labor market needs; (27) develop curriculum assessment system; (28) develop and deploy the independent schools model to reach 2000 public schools run by small establishments; (29) develop life-long learning and sustainability; (30) develop an awareness program on investment and entrepreneurship for high schools and university students; (31) enhance the image of the education system in the Kingdom of Saudi Arabia; (32) foster the role of the family in the educational process and promote national identity; develop digitization and GIS information system; (34) establish a database of education statistics, alumni and scientific research; (35) establish an office of strategy management at the ministry level; and (36) develop key performance indicators at ministry level.

Implementation of the listed 36 Ministry of Education initiatives commenced in 2016 as part of the National Transformation Program's 2020 function of supporting the Saudi Vision 2013. The initiatives have been scheduled for five years from 2016 and are to be transparent and goal and achievement driven and measured.

\section{Saudi Vision 2030}

The National Transformation Program 2020 describes the Saudi Vision 2030 as being a methodology and the roadmap for development where the resultant actions will position the Kingdom of Saudi Arabia as a leader in all fields. In essence the Vision is so much more; providing the Kingdom with the directions, commitment, goals, and objectives to achieve its identified aspirations and define itself nationally, regionally, and globally. The Vision is descriptive in nature on how the Kingdom envisages achieving its aspirations, while at the same time demonstrates commitment, support and collective motivation to deliver the outlined aspirations for the citizens of the Kingdom. The Saudi Vision 2030 provides macro longer term goals for the Kingdom and how it sees itself positioned nationally, regionally, globally, and at the heart of the Arab and Islamic world, which is the first pillar of the Vision.

The second pillar of the Vision is to become a global investment powerhouse. This includes the goal of transforming the Public Investment Fund into the world's largest sovereign wealth fund, initially through the partial floating of Saudi Aramco but also through economic expansion, local production and manufacturing, and bureaucratic reform and transparency in the private and public sectors. The third pillar can be seen to be implicitly tied to the second pillar in that the Vision seeks to establish the Kingdom through its strategic location as the connector of three continents; Asia, Europe, and Africa. Key to realizing the achievement of these two clearly defined pillars is recognizing and building upon on an economy that is not solely reliant of oil for both its energy and economic needs. Whilst the Kingdom is diversely resource rich and can leverage and exploit further 
land mining activities to support economic development the Vision recognizes that the driving collective resource for the Kingdom of Saudi Arabia is the younger generation who have the capability and motivation to drive the diversification of the Kingdom's economy and future.

The Kingdom has begun to put in place measures to increase the achievement of the three pillars, particularly the second and third pillars through legislation to create jobs for Saudis, where the Kingdom has the young talent to populate and achieve in the private sector through both quality education 'at home' and the large scale international scholarship program that has been open to young Saudis for over a decade. The scholarship program has been scaled back to ensure those applying and receiving scholarships are studying at the highest quality international institutions and are majoring in areas seen as beneficial to economic diversity of the economy and specialist skills areas. These initiatives will contribute to further Saudization through putting the interests, well-being, and opportunities for its citizens 'front and center'. The authors of this article would suggest the Kingdom of Saudi Arabia is taking a far more proactive approach demonstrating this commitment to its citizens than other nations.

The National Transformation Program 2020 is the initial platform the Kingdom has developed to 'set the Kingdom on the path' to achieving the longer term aspirations of the Saudi Vision 2030. As highlighted in the discussion and National Transformation Program 2020 document analysis, continued education development needs to be at the forefront of Kingdom's strive and ambition for the achievement of its outlined micro and macro goals, both short and longer term.

The Saudi Vision 2030 "is built around three themes: a vibrant society, a thriving economy, and an ambitious nation" (Kingdom of Saudi Arabia, 2016b, p. 13). These themes support the building of and reflect the sediment of the three pillars. The first theme, a vibrant society encompasses citizenship, healthy lives and social and health care provision and access, development of cities, environmental sustainability, increase in the number of cultural and entertainment options, family relationships and care for families, engagement of families in their children's education, developing children's character, empowering society, national unity, and cultural heritage. This theme is underpinned by following Islamic principles and the importance of Islamic values and Islam's guidance, which will be the impetus for the Kingdom realizing its Vision. The Vision states, "the values of moderation, tolerance, excellence, discipline, equity, and transparency will be the bedrock of our success" (Kingdom of Saudi Arabia, 2016b, p. 15). Additionally, the Vision provides commitment to attending to the needs of the increasing number of pilgrims and Umrah visitors whose numbers continue to increase year-on-year.

The second theme, a thriving economy is education reliant by linking education to economic growth, a focus on the provision of education and training that leads to employment outcomes for the younger generation, and growth in private providers in the Kingdom. This theme demonstrates commitment to boosting the role of small and medium sized businesses, equal opportunities, maximization of investment capability, privatization of (some) government services and improving the business environment, support for new initiatives and sector development, localized defense industries, diversification of the mining industry, expanding the renewable energy sector and increasing the competitiveness of the energy sector, restructuring of the King Abdullah Financial District and rehabilitating economic cities, establishing special zones and constructing a regional logistics hub, development of digital infrastructure, operation of a vibrant retail sector anchored by Saudization, and supporting national companies. An evident recurring theme in this article is putting the interests and well-being of Saudi Arabians at the forefront of the Kingdom's aspirations and initiatives. However, in the context of this analysis it is important to note that the Kingdom along with attracting the best Saudi minds, also seeks to attract and retain the best foreign minds to contribute to achieving and exceeding the Kingdom's goals. These key points highlight that the Kingdom is 'open for business'.

The third theme is an ambitious nation that is effectively governed. The Vision recognizes the importance of continued improvement and the need for government to evolve to meet new challenges. This theme highlights the need for transparency; both financially and administratively and these stated goals are being achieved already through the National Transformation Program 2020 and the publishing of goals, plans, and performance so progress can be measured. This is being encouraged through the engagement of citizens and the private sector and is being achieved through smart systems; interactive and online. The third theme also identifies the importance of protecting the Kingdom's resources and seeking partnerships with countries that have an abundance of natural resources the Kingdom lacks; for example water and fertile soil. Additionally, the third theme seeks a responsible nation; individually, in business, collectively, and to society.

There are initial additional programs that the Kingdom has introduced to contribute the achieving the Vision. These programs include: government restructuring; strategic direction; fiscal balance; project management; 
regulations review; performance measurement; Saudi Aramco strategic transformation; Public Investment Fund restructuring; human capital; strategic partnerships; privatization; and strengthening public sector governance. These programs will increase transparency in both the private and public sectors, facilitate less complex private investment procedures, encourage entrepreneurship, increase private sector employment and growth, and improve the efficiency and effectiveness of the public sector to make it more accountable to the public.

\section{Discussion}

This article sought to identify through a document analysis, the orientations to curriculum in the National Transformation Program 2020. Further, the article provided an overview of the Saudi Vision 2030 and examined the influences upon the development of these strategic programs, plans, and initiatives through an overview of the Ninth Development Plan $(2010$ - 2014). This document was analyzed to provide insight into how the Kingdom of Saudi Arabia has sought to define itself, both historically and currently.

The analysis reveals some key findings. First, the orientations to curriculum that need to be embedded in current and future curricula for the Kingdom to realize the goals of the Saudi Vision 2030 are the first segment of social adaptation where the focus of curricula is on producing graduates to meet the economic needs of a country. That is to produce graduates who are qualified to meet the needs of the (private sector) labor market. Additionally, Eisner's (1985) orientation to curriculum, curriculum as technology where the focus is on curriculum planning, purpose, and goals with an emphasis on evaluation of the efficiency and effectiveness of the curriculum needs to be embedded in current and future curricula. This orientation to curriculum will ensure transparency, accountability of the education system, and that the goals of curricula are aligned with the collective micro and macro goals of the Kingdom.

Second, the Kingdom of Saudi Arabia is consciously trying to define itself through the National Transformation Plan 2020 and Saudi Vision 2030. To contribute to the achievement of the Kingdom's goals well-articulated curriculum intent needs to be apparent throughout the education system. These curriculum intentions need to include a variety of curriculum orientations and foundations including progressivism, reconstructionism, the development of cognitive processes, and academic rationalism. These core curriculum intentions will provide an explicit demonstration of a nation committed, through educational processes, to cultivating, and potentially reconstructing its future citizens and society that is academically oriented and prepared; possessing the critical thinking skills that will shape the future of the Kingdom of Saudi Arabia in its drive to move towards a knowledge-based economy. The development of creativity and innovation are essential elements in progress towards a knowledge-based economy and society (De Beule \& Nauwelaerts, 2013). Professional development programs for teachers and monitoring and evaluation of teachers by ministry of education supervisors will attempt to ensure that the Kingdom of Saudi Arabia has the human teaching resources to develop inquiry and creativity in the education system.

The third key point to emerge from the document analysis is the increasing and overt evidence of a focus on the relationship and alignment between national education goals and economic development. This is a global phenomenon as is stated in The Global Competitiveness Report 2015-2016 (Schwab \& Sala-i-Martín, 2015, p. xiii), "across countries we are witnessing economic policymaking become increasingly people-centred and embedded in overall societal goals". Additionally, the documents increasingly provide evidence of goals for the younger generation to develop the necessary skills during their education that will support them to become economically productive members of Saudi society as education becomes influenced by the economic agenda (Connell, 2013).

The fourth and final key point is the emphasis on where the Kingdom of Saudi Arabia sees itself positioned globally. It wants its students and workforce to have the knowledge and skills that are required to interact within the region as well as globally. There is an emphasis on learning about local and regional culture and current events while raising the Kingdom of Saudi Arabia's intellectual standing and participation in the global community. In essence, the documents signal to students that they need to gain local and regional knowledge and to provide the Kingdom of Saudi Arabia with an international intellectual presence that will contribute to the Kingdom's global standing.

To address these key points, necessary for achieving the Kingdom's goals and aspirations, Maroun, Samman, Moujaes, and Abouchakra (2008) highlight that, "Gulf Cooperation Council Countries can improve their economic competitiveness by improving the quality of their education systems. An effective education framework must be instituted to optimize the channelling of funds and allow for a better return on investments" (p. 6). Maroun et al. (2008) also discuss the need for Gulf Cooperation Council Countries to better equip students with soft skills such as communication, problem solving, and negotiation skills. These soft skills are what Saudi 
youth have also identified as lacking in the Saudi Arabian education system (Boston Consulting Group, 2014). The improvement in the quality of education should be measured and aligned with economic indicators and not only school enrolment data (Hanushek \& Wößmann, 2007).

A final important element is to increase parental participation in the educational process. Research further indicates that parental participation in their children's schooling has positive effects on children's success with increased motivation, homework completion rates, and improved academic achievement being some of the benefits (Abdullah et al. 2011).

\section{Summary}

The purpose of the this article has been to provide an analysis of the National Transformation Program 2020 and the Saudi Vision 2030, both of which are providing the stimulus and drive for the current and future Saudi generations to define themselves. As prelude to the overview of these potentially nation defining documents, this article provided commentary on the Kingdom's Ninth Development Plan (2010 - 2014).

The National Transformation Program 2020 and the Saudi Vision 2030 identify the development and employment of the national workforce, particularly through increased participation in the private sector; and providing the younger generation with the necessary skills during their education that will support them to become economically productive members of Saudi society as key factors in the Kingdom's continuing development. However, the documents make it clear the Kingdom encourages human capital and expertise from abroad that will add value to what the Kingdom is seeking to achieve as a nation. These goals are supported by three key pillars; to be positioned at the heart of the Arabic and Islamic world, to become a global investment powerhouse, and to be the connector of Asia, Europe, and Africa.

While the documents can be seen to be economically focused they are underpinned by themes, which provide the social and moral compass or perhaps guidance by the Kingdom's traditional and religious values. The first theme, a vibrant society highlights this with the Kingdom's citizens following Islamic principles and Islam's guidance. The second theme is a vibrant economy with less of a reliance of oil and engagement and employment of Saudis, which is supported by the third theme of an ambitious nation, which is effectively governed. For the Kingdom of Saudi Arabia to meet and exceed its aspirations and goals presented in its Transformation Program 2020 and the Saudi Vision 2030, education and training are going to be vital components in the Kingdom's journey towards a knowledge-based society and diversified economy.

\section{References}

Abdullah, A. G. K., Seedee, R., Alzaidiyeen, N. J., Al-Shabatat, A., Alzeydeen, H. K., \& Al-Awabdeh, A. (2011, August). An investigation of teachers' attitudes towards parental involvement. Educational Research, 1402-1408.

Retrieved from http://www.interesjournals.org/full-articles/an-investigation-of-teachers-attitudes-towards-parental-involve ment.pdf?view=inline

Boston Consulting Group. (2014). What matters most to Saudi Arabia's youth? Helping policy makers address the national challenges.

Bowen, G. A. (2009). Document Analysis as a Qualitative Research Method. Qualitative Research Journal, 9 , 27-40. https://doi.org/10.3316/QRJ0902027

Braun, V., \& Clarke, V. (2006). Using thematic analysis in psychology. Qualitative Research in Psychology, 3(2), 77-101.

Commins, D. D. (2008). The Wahhabi Mission and Saudi Arabia. London, United Kingdom: I.B.Tauris \& Co. Ltd.

Connell, R. (2013). The neoliberal cascade and education: an essay on the market agenda and its consequences. Critical Studies in Education, 54(2), 99 -112. https://10.1080/17508487.2013.776990

De Beule, F., \& Nauwelaerts, Y. (2013). Innovation and creativity: Pillars of the future global economy. London, United Kingdom: Edward Elgar Publishing.

Eisner, E. (1985). Five basic orientations to the curriculum. In the educational imagination: on the design and evaluation of school programs. New York, NY: Macmillan.

General Authority for Statistics, Kingdom of Saudi Arabia. (2018). Tenth development plan. Retrieved from https://www.stats.gov.sa/en/page/72 
Hanushek, E. A., \& Wößmann, L. (2007). Education quality and economic growth. Washington, DC: The International Bank for Reconstruction and Development /The World Bank.

Habtor, A. (2015, August 16). More jobs off-limits to expats. The Arab News. Retrieved from http://www.arabnews.com/saudi-arabia/news/792061

Kingdom of Saudi Arabia. (2016a). National Transformation Program 2020. Retrieved from http://vision2030.gov.sa/sites/default/files/NTP_En.pdf

Kingdom of Saudi Arabia. (2016b). Vision 2030 Kingdom of Saudi Arabia. Retrieved from http://vision2030.gov.sa/en

Labuschagne, A. (2003, March). Qualitative research: Airy fairy or fundamental? The Qualitative Report, 8(1). Retrieved from http://www.nova.edu/ssss/QR/QR8-1/.html

Manley-Delacruz, E. (1990). Revisiting curriculum conceptions: a thematic perspective. Visual Arts Research, $16(32), 10-25$.

Maroun, N., Samman, H., Moujaes, C. N., \& Abouchakra, R. (2008). How to Succeed at Education Reform: The Case for Saudi Arabia and the Broader GCC Region. Booz \& Co. Retrieved from http://www.ideationcenter.com/media/file/How_to_Succeed_at_Education_Reform_FINAL.pdf

Ministry of Economy and Planning, Kingdom of Saudi Arabia. (2000). Eighth Development Plan (2005-2009).

Ministry of Economy and Planning, Kingdom of Saudi Arabia. (2010). Ninth Development Plan (2010 - 2014).

Schwab, K., \& Sala-i-Martín, X. (2015). The global competitiveness report 2015-2016. Geneva, Switzerland: World Economic Forum.

Taba, H. (1962). Curriculum development: Theory and practice. New York, NY: Harcourt, Brace \& World Inc. 
Appendix A

Identified Curriculum Orientations within the National Transformation Program 2020's Education Related Initiatives

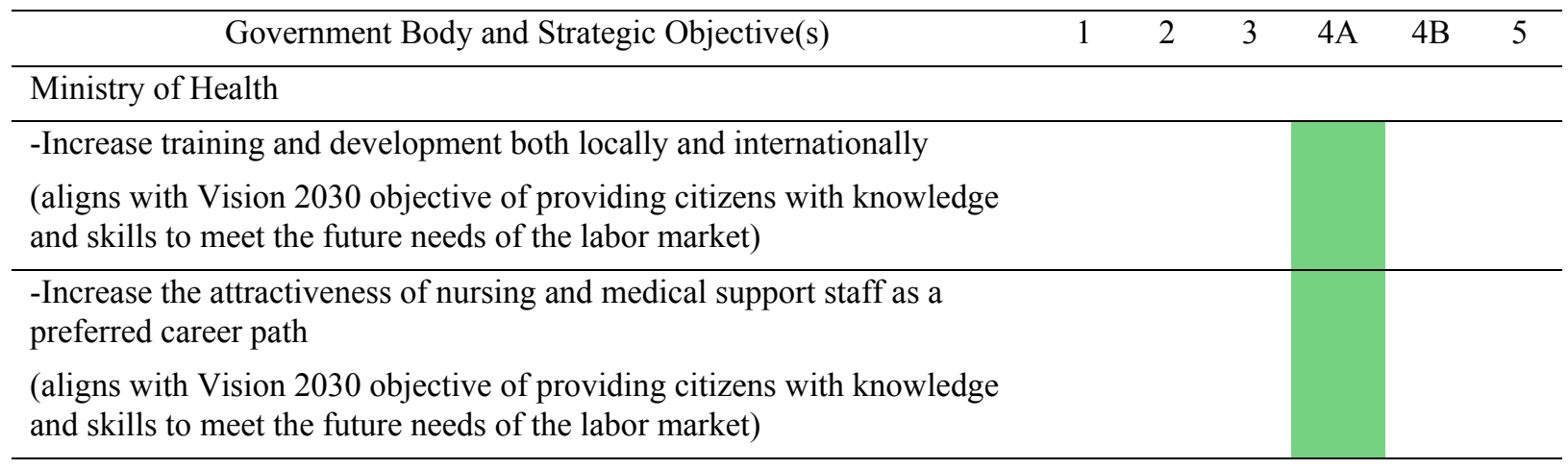

\begin{tabular}{l}
\hline Ministry of Communications and Information Technology \\
\hline -Bridge the digital gap in the skills of ICT users (aligns with Vision 2030 \\
objective of Provide citizens with knowledge and skills to meet the future \\
needs of the labor market) \\
\hline -Increase the IT industry's contribution in the non-oil GDP (aligns with \\
Vision 2030 objective of providing citizens with knowledge and skills to \\
meet the future needs of the labor market)
\end{tabular}

\begin{tabular}{l}
\hline Ministry of Commerce and Investment \\
\hline -Increase the culture of entrepreneurship (aligns with Vision 2030 \\
objectives of boosting entrepreneurship; and developing youth skills and \\
leveraging them effectively)
\end{tabular}

\begin{tabular}{l}
\hline The Ministry of Labor and Social Development \\
\hline -Develop quality standards and technical professional accreditation \\
(aligns with Vision 2030 objective of providing citizens with knowledge \\
and skills to meet the future needs of the labor market) \\
\hline -Raise Saudis skill level to match labor market needs (aligns with Vision \\
2030 objective of providing citizens with knowledge and skills to meet \\
the future needs of the labor market) \\
\hline -Increase the capacity of technical and vocational training institutions and \\
link it to the \\
labor market needs (aligns with Vision 2030 objectives of providing \\
citizens with knowledge and skills to meet the future needs of the labor \\
market; and developing youth skills and leveraging them effectively)
\end{tabular}

\begin{tabular}{l}
\hline Ministry of Education \\
\hline -Provide education services for all student levels (aligns with Vision 2030 \\
objectives of establishing positive values and build an independent \\
personality for citizens; and \\
providing citizens with knowledge and skills to meet the future needs of \\
the labor market) \\
\hline -Improve recruitment, training and development of teachers (aligns with \\
Vision 2030 objectives of establishing positive values and build an \\
\hline
\end{tabular}


independent personality for citizens; and

providing citizens with knowledge and skills to meet the future needs of the labor market)

-Improve the learning environment to stimulate creativity and innovation (aligns with Vision 2030 objectives of establishing positive values and build an independent personality for citizens; providing citizens with knowledge and skills to meet the future needs of the labor market; and developing youth skills and leveraging them effectively)

-Improve curricula and teaching methods (aligns with Vision 2030 objectives of establishing positive values and build an independent personality for citizens; and providing citizens with knowledge and skills to meet the future needs of the labor market)

-Improve students' values and core skills (aligns with Vision 2030 objectives of establishing positive values and build an independent personality for citizens; and providing citizens with knowledge and skills to meet the future needs of the labor market)

-Enhance the educational system's capability to address national development requirements

and to meet labor market demands (aligns with Vision 2030 objective of providing citizens with knowledge and skills to meet the future needs of the labor market)

-Increase private sector participation in the education sector (aligns with Vision 2030 objective of providing citizens with knowledge and skills to meet the future needs of the labor market)

\begin{tabular}{l}
\hline Royal Commission for Jubail and Yanbu \\
\hline -Improve the quality of education outputs and provide a qualified national \\
workforce to \\
investors in the cities (aligns with Vision 2030 objective of providing \\
citizens with knowledge and skills to meet the future needs of the labor \\
market)
\end{tabular}

\footnotetext{
King Abdulaziz City for Science and Technology

-Support local content through development of nationally-qualified professionals (aligns with Vision 2030 objectives of providing citizens with knowledge and skills to meet the future needs of the labor market; and developing youth skills and leveraging them effectively)

Key: 1. Academic rationalism 2. Development of cognitive processes 3. Personal relevance 4A. Social adaptation 4B. Social reconstruction 5. Curriculum as technology
} 